\title{
Die Mathematik des Lebens
}

\section{Erhard Taverna}

Dr. med., Mitglied der Redaktion

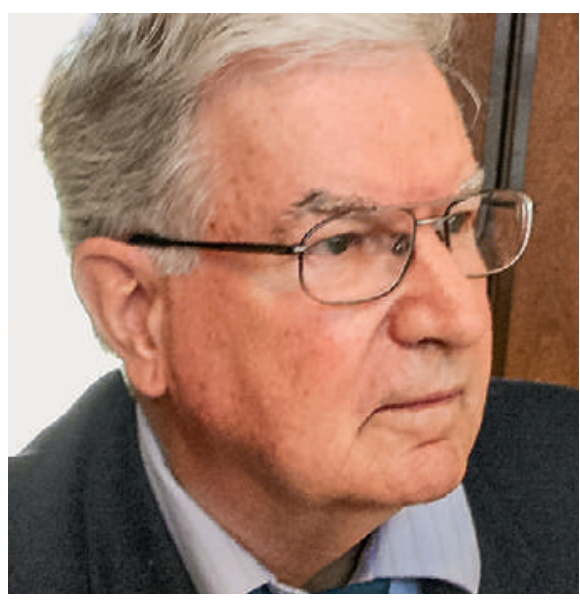

Vielschreiber, Vielreisender und Vieldenker: Psychiater Niklaus Gaschen.
Niklaus Gaschen, Jahrgang 1942, ist praktizierender Psychiater und Psychotherapeut mit eigener Praxis in Bern. Ein Vielschreiber, Vielreisender und Vieldenker. Während seinen sieben Jahren in Finnland habe er «einige Zeit den Birken zugeschaut» und dabei existentielle Zusammenhänge begriffen. Zum Beispiel die, dass der Lebensraum des Menschen, den Gesetzmässigkeiten des Kosmos unterstellt, sich genauso mathematisch beschreiben lasse, wie es die Physik unternimmt. Niklaus Gaschen hat seine Existenzphilosophie aus den Praxiserfahrungen weiterentwickelt und seine Lehre Anankologie (altgriechisch Schicksal, Notwendigkeit, Naturgesetz) genannt. Er stellt sich in die Tradition des Psychologiepioniers Kurt Lewin, dessen Feldtheorie und vektorielle Topologie massgeblich zur Erforschung der Gruppendynamik, vor allem von Selbsthilfegruppen, beitrugen. Das einführende Lehrbuch des Facharztes für ein neues Denken und Handeln in Wissenschaft und Praxis, von ihm auch als vektorielle Philosophie bezeichnet, stehe weltweit in vielen Bibliotheken, habe aber leider bisher keine grössere Nachfrage ausgelöst. Von 1988 bis 1996 wurden seine kulturphilosophischen Studien in einem Verein mit einer eigenen Zeitschrift debattiert und vertieft. Seine Anankologie erklärt der Autor in 18 Theoremen, die nicht einfach zu verstehen sind. Er unterscheidet darin vier grosse Kategorien, unterteilt in Bio-, Psycho-, Situations- und Residualvektoren, aus deren Summe er einen theoretisch genauen und praktisch immerhin wegweisenden Existenzvektor ableiten will. Eine Universallehre, die unter anderem Einsteins Physik und die Krankheitspathologie in einem viel-dimensionalen, mathematischen Konstrukt vereinigt.

Seit 1988 als freier Schriftsteller tätig, lebt Niklaus Gaschen alleine, was ihm jede Menge Zeit zum Nachdenken erlaube. Nachts kämen ihm von selbst die Ideen und Konzepte, einmal skizziert, brauche er nur wenige Tage, um eine Vorstellung schriftlich auszuarbeiten. Soeben ist das 21. Buch erschienen, ebenfalls beim Verlag Haag \& Herchen, der seit Jahren Band um
Band veröffentlicht. Geplant sind für dieses Jahr drei Romane und im nächsten Jahr ein erster Leseband zur «Praxis der Vektoriellen Philosophie». Das rastlose Schreiben ist seine Welt, ist Selbsterfahrung, Therapie und Überlebenshilfe. In einem vorläufig letzten, literarischen Reisebericht Auf der Suche nach dem Golem beschreibt er auf seinen Streifzügen durch Prag, neben Franz Kafka und dem Golem-Mythos, das Leben von Egon Erwin Kisch (1885-1948), der über seine Zeit hinaus als "rasender Reporter» bekannt blieb. Ein hektischer Weltreisender, der den modernen Reportagestil des engagierten, subjektiven Berichters populär machte. Eine faszinierende Figur, die den Reporter Niklaus Gaschen vielleicht auch ganz persönlich anspricht.

Auf die heutige Praxis und Ideologie der IV ist der Psychiater nicht gut zu sprechen. In einem alarmierten und empörten Rundmail Vom Stand der Dinge und kollektiver Mitschuld macht er den asozialen und antipsychiatrischen Gesinnungswandel unserer Gesellschaft für den willentlich herbeigeführten Absturz der Germanwings-Maschine mitverantwortlich. Ein selbstmörderischer Linienpilot, der allen Kontrollinstanzen entging, und sei es auch nur, weil diese, um Kosten zu sparen, abgebaut wurden und psychisch Kranken oft eine berufliche Invalidisierung abgesprochen wird.

Der philosophierende und schreibende Psychiater aus Bern ist ein ruhiger und besonnener Mensch. Er weiss, dass die Schicksalsgöttin Ananke viele Sprachen spricht. Die mathematische sei allerdings die präziseste und abstrakteste. Von den Computer-Algorithmen eines «Brain-Projektes» in Lausanne erwartet er nicht die Lösung für das hochkomplexe, nicht einmal von Giga-Rechnern simulierbare System Mensch. Doch immerhin einen substantiellen Beitrag zum Verständnis neuronal-vektoriell-mathematischer Abläufe, die unsere Existenz mitbestimmen. Unser Leben sei vieldimensional, meint er nachdenklich und bescheiden. Seine Biographie gäbe dazu eine gute Vorlage ab. Ein offener Tagebuchschreiber, interessiert und belesen, der uns auf seine Reisen mitnimmt, an seinen Träumen, Fantasien und Hoffnungen teilnehmen lässt, über das Geschriebene Gesellschaft sucht, vielleicht auch Geborgenheit. Ein beobachtender Chronist, ein Suchender. Einerseits ein einsamer Mann, andererseits aufgehoben in einer Leserschaft, die sich in seinen zahlreichen Werken selber erkennt. 